\title{
Pathophysiology and pathological findings of heatstroke in dogs
}

This article was published in the following Dove Press journal:

Veterinary Medicine: Research and Reports

8 January 2013

Number of times this article has been viewed

\section{Mariarita Romanucci Leonardo Della Salda \\ Department of Comparative Biomedical Sciences, Faculty of Veterinary Medicine, University of Teramo, Teramo, Italy}

Correspondence: Mariarita Romanucci Department of Comparative Biomedical Sciences, Faculty of Veterinary Medicine, University of Teramo, Piazza A Moro 45, 64100 Teramo, Italy

Tel +390861266890

Fax +3908 6I26 6865

Email mromanucci@unite.it

\begin{abstract}
Canine heatstroke is a life-threatening condition resulting from an imbalance between heat dissipation and production, and characterized by a nonpyrogenic elevation in core body temperature above $41^{\circ} \mathrm{C}\left(105.8^{\circ} \mathrm{F}\right)$. Several exogenous and endogenous factors may predispose dogs to the development of heatstroke; on the other hand, adaptive mechanisms also exists which allow organisms to combat the deleterious effects of heat stress, which are represented by the cellular heat-shock response and heat acclimatization. The pathophysiology and consequences of heatstroke share many similarities to those observable in sepsis and are related to the interaction between the direct cytotoxicity of heat, the acute physiological alterations associated with hyperthermia, such as increased metabolic demand, hypoxia, and circulatory failure, and the inflammatory and coagulation responses of the host to the widespread endothelial and tissue injuries, which may culminate in disseminated intravascular coagulation, systemic inflammatory response syndrome, and multiple organ dysfunction.
\end{abstract}

Keywords: thermoregulation, acclimatization, heat shock proteins, hyperthermia, systemic inflammatory response, multiple organ dysfunction

\section{Introduction}

Heatstroke is an acute, rapidly progressive life-threatening condition, commonly recognized in dogs and characterized by a nonpyrogenic rise in core body temperature above $41^{\circ} \mathrm{C}\left(105.8^{\circ} \mathrm{F}\right)$ that causes direct hyperthermal injury to tissues, especially central nervous system, possibly leading to multiple organ dysfunction. ${ }^{1}$ It results from an imbalance between heat-generating and heat-dissipating mechanisms, and requires prompt, aggressive therapeutic intervention and continuous critical-care monitoring to avoid serious secondary complications and death..$^{2-4}$

Heatstroke is the most severe form of heat-induced illness, which is classified on the basis of the type and severity of clinical signs in humans. ${ }^{5-7}$ The least severe is heat cramps, characterized by extreme dehydration, muscle cramps, and sodium chloride depletion, but it is rarely recognized in veterinary patients. ${ }^{6}$ Heat exhaustion is a more distinct clinical entity characterized by lethargy and inability to perform work resulting from water and salt depletion, whereas heat prostration is more severe and is characterized by headache, vomiting, tachycardia, and hypotension in humans. ${ }^{5-7}$ In small animals, early signs of overheating include excessive panting, elevated heart rate, hypersalivation and weakness, while dry gums, nausea, and vomiting may appear as the condition progresses towards heat prostration. This last condition may occur with acute elevations of body temperature ranging from $>40^{\circ}$ to $41^{\circ} \mathrm{C}\left(104^{\circ} \mathrm{F}-105.8^{\circ} \mathrm{F}\right)^{8}$ submit your manuscript | www.dovepress.com

Dovepress

http://dx.doi.org// 0.2147/VMRR.S29978
Veterinary Medicine: Research and Reports 2013:4 I-9

(C) 2013 Romanucci and Della Salda, publisher and licensee Dove Medical Press Ltd. This is an Open Access article which permits unrestricted noncommercial use, provided the original work is properly cited. 
and may rapidly progress to heatstroke, which is associated with the appearance of signs of central nervous system dysfunction.

Most of the information concerning heatstroke syndrome in veterinary medicine has been derived from human medicine. ${ }^{3,5,6}$ However, dogs are considered unsuitable models for human heat-related disease because of differences in responses to high temperature, ${ }^{9}$ particularly in light of the intrinsic thermal resistance of canine brain. ${ }^{10}$ In this respect, it is also important to remember the existence of a cooling system for a dog's brain, constituted by the carotid rete mirabile, a network of blood vessels branching from the carotid artery, which passes through a venous sinus, drawing cooled blood from the nasal cavity. In this rete mirabile, the warm arterial blood exchanges heat with the cooler venous blood, consequently cooling the blood supply to the brain. ${ }^{11}$ This system is also typically recognized to exist in almost all mammalian species belonging to the order Artiodactyla, as well as in various species of the Felidae family, including the cat, but it is lacking in species belonging to the mammalian orders Primates, Perissodactyla (such as horses), Rodentia, and Lagomorpha. ${ }^{11-15}$

\section{Systemic and cellular responses to heat stress \\ Thermoregulation}

Homeostatic mechanisms of thermoregulation function keep body temperature within a narrow range (called the "set-point"), by maintaining the balance between heat production and dissipation. The thermoregulatory center is located in the preoptic region of the anterior hypothalamus, where numerous thermoreceptors exist, whose signals converge in the caudal hypothalamus, in association with those signals originating from temperature-sensitive organs (ie, skin, viscera, central nervous system), leading to the activation of neurohormonal compensatory responses aimed to maintain an almost constant core body temperature. ${ }^{6}$ Body heat is generated from metabolism and muscular activity (endogenous source) and gained from the environment (exogenous source), whereas it is dissipated by four cooling mechanisms, represented by radiation, conduction, convection, and evaporation. ${ }^{4,6}$ At ambient temperatures below $32^{\circ} \mathrm{C}\left(89.6^{\circ} \mathrm{F}\right)$, more than $70 \%$ of the total body heat loss in dogs is due to radiation and convection from the body surface. ${ }^{1,6,16,17}$ Radiation involves the electromagnetic transfer of heat from the body to the environment, while convection is the exchange of heat between the body and cooler air continuously passing over skin, as occurs with a fan or with wind. ${ }^{4}$ On the other hand, conduction usually accounts for only a small portion of the animal's heat dissipation, ${ }^{8}$ although it may play a greater role in dogs lying down on cool surfaces, aided by peripheral vasodilation and increased cutaneous circulation occurring during warm environmental temperatures. ${ }^{6}$ However, as the environmental temperature increases approaching body temperature, evaporation, primarily occurring through panting, becomes the most important mechanism for dissipating body heat in dogs. ${ }^{1,4,6}$ Activation of the panting center is the initial compensatory response to increased ambient heat in dogs, which allows large quantities of air to be brought into contact with the wide evaporative surface area provided by the moist mucous membranes of the nasal turbinates and the oral cavity, also favored by increased salivation. ${ }^{4,6,16}$ However, panting requires respiratory muscle activity that generates heat in itself; ${ }^{6}$ as well, hyperventilation may cause respiratory alkalosis. ${ }^{16}$

Blood temperature elevations of less than $1^{\circ} \mathrm{C}\left(1.8^{\circ} \mathrm{F}\right)$ are sensed by the peripheral and central thermoreceptors, which then switch on the hypothalamic thermoregulatory center, whose efferent responses are mediated by sympathetic nervous and endocrine system activation, and include constriction of renal and splanchnic blood vessels and cutaneous vasodilation, causing a shift of heated blood from the core circulation to the body surface. Cardiovascular response to heat stress also implies tachycardia and increased cardiac output. Consequently, an inability to increase cardiac output because of salt and water depletion, cardiovascular diseases, or drugs interfering with cardiac function can impair thermoregulation, resulting in increased susceptibility to heatstroke. Dehydration can also impair thermoregulation by decreasing heat loss via evaporation, as well as through radiation and convection because of decreased blood flow to the peripheral vessels. $^{4,6,16,18}$

\section{Acclimatization}

Acclimatization is a time-dependent process involving adaptive, integrative physiological changes that improve the body's ability to cope with extreme environmental temperatures. ${ }^{19}$ It is obtained through continuous or repeated challenge of the thermoregulatory system by a hot environment and takes time to develop but is long acting (several weeks). ${ }^{20}$ In animals, this process may be partially completed over 10-20 days, similarly to humans, but even 2 months may be needed for full acclimatization; $;^{2,4,21}$ it involves enhancement of cardiovascular performance, activation of the renin-angiotensin-aldosterone axis, salt conservation, expansion of plasma volume, increase in the glomerular 
filtration rate, and increase in the ability to resist exertional rhabdomyolysis. ${ }^{18}$ Acclimatory homeostasis is manifested by a widened dynamic thermoregulatory range, reflected by a lower temperature threshold for heat dissipation, and a delayed threshold for developing thermal injuries. ${ }^{19,20}$ This implies increased capacity of the thermal effectors for heat dissipation, reduced heat production, and under certain circumstances, expanded body core temperature safety margins. Features of the acclimated status include lowered core temperature, reduced heart rate, elevated cardiovascular reserve, and increased capacity for evaporative cooling. ${ }^{20}$

\section{Acute-phase response}

The acute-phase response to heat stress is a coordinated systemic reaction that involves endothelial cells, leukocytes, and epithelial cells, aimed to reestablish homeostasis by protecting tissues from damage by the inflammatory process and promoting resolution and healing. ${ }^{18,22,23}$ Organisms are known to produce a number of cytokines in response to endogenous or environmental heat, including tumor necrosis factor (TNF)- $\alpha$, interleukin (IL)-1, IL-6, IL-8, IL-10, and IL-12. These cytokines mediate fever, leukocytosis, increased synthesis of acute-phase proteins, muscle catabolism, stimulation of the hypothalamic-pituitary-adrenal axis, and activation of leukocytes and endothelial cells. ${ }^{18}$ The IL-6 produced during heat stress is the major modulator of local and systemic acute inflammatory responses by controlling the levels of inflammatory cytokines; it also stimulates liver production of anti-inflammatory acute-phase proteins, which inhibit the production of reactive oxygen species and the release of proteolytic enzymes from activated leukocytes. ${ }^{7,18,24}$ However, the acute-phase response can be protective or not, depending on the combined effects of the different mediators, and the imbalance between pro-inflammatory and anti-inflammatory factors produced. Over-intensity of the acute-phase response and development of a predominantly inflammatory condition may favor the progression from heat stress to heatstroke. ${ }^{4,18}$

\section{Heat shock response}

Another mechanism of adaptation to heat occurs at the cellular level and is defined as thermotolerance. It is caused by a single, severe but nonlethal heat exposure that allows cells to survive a subsequent and otherwise lethal heat stress. Achievement of the thermotolerant status is based on the activation of the heat shock response; that is, a rapid, short-acting (a few days) molecular process associated with the synthesis of heat shock proteins (HSPs). ${ }^{20,25}$ HSPs, also known as "stress proteins" (named according to their molecular weight), are a large class of proteins that have been highly conserved throughout evolution and are expressed by both prokaryotic and eukaryotic organisms. HSPs control protein biogenesis by assisting in the correct folding of newly formed polypeptides, oligomeric assembly, and intracellular translocation, also preventing inappropriate stress-induced protein aggregation by assisting in the repair of denatured proteins or by promoting their degradation. As a result of these roles, HSPs are crucial in the maintenance of cellular homeostasis, and they have also been referred to as molecular "chaperones," which help the cell to maintain intracellular functions and structural protein stability under both physiological and stress conditions. ${ }^{26-28}$ HSPs are socalled because their expression was initially discovered to be induced by heat shock. ${ }^{29,30}$ However, since then, a wide variety of environmental and metabolic factors including hypoxia, oxidative injury, glucose starvation, or exposure to heavy metals have been shown to elicit stress protein expression. Therefore, cellular stress response is a unique and important defense mechanism put into action by the cell to cope with a wide range of harmful conditions. ${ }^{27}$ This response includes increased HSP synthesis, which has been detected in many pathophysiological conditions such as tissue injury and repair, fever, inflammation, and viral and bacterial infections. ${ }^{31}$

\section{Role of HSPs in heat adaptation and protection against heatstroke-induced injuries}

The HSP70 family is thought to be the most responsive to heat stress. ${ }^{20}$ The mechanism by which HSPs confer stress tolerance to cells is not completely defined but may be related to their essential functions in denatured protein management, protein translocation across membranes, and cytoskeletal stabilization. ${ }^{25,32}$ HSPs may also offer protection against apoptotic and necrotic cell death, ${ }^{33,34}$ as well as oxidative stress. ${ }^{35}$ It has been demonstrated that heat shock pretreatment induces Hsp72 overexpression in striatum and confers protection against heatstroke-induced arterial hypotension, striatal ischemia, and damage by reducing oxidative stress and energy depletion. ${ }^{36}$

A growing body of evidence also suggests the role for HSPs in the whole organism's adaptation to heat other than through thermotolerance. In fact, in addition to the rapid heat shock response, chronic exposure to moderate heat may induce HSP accumulation, and since HSPs overexpression in cultured cells elevate the degree of the lethal temperature, 
their accumulation on long-term heat acclimatization could also contribute to the elevation of the upper body core temperature safety margin and reduce heat illness risk..$^{20,37-39}$ In this respect, comparisons of Hsp70 levels between organisms inhabiting either normothermic or hot environments showed that the hot-environment species have higher HSP levels compared with species of the same genus inhabiting normothermic environments. ${ }^{20}$ Hsp72 overexpression in multiple vital organs including the heart and the brain has been demonstrated to confer protection against heatstrokeinduced hyperthermia, circulatory shock, and cerebral ischemic injury in rats and mice. ${ }^{40-43}$ On the other hand, circulating Hsp72 levels have been suggested to be a candidate marker of the extent of tissue damage and necrotic cell death during heatstroke. ${ }^{44}$ A possible mechanism by which Hsp70 protects against heatstroke-induced hemodynamic dysfunctions may involve the potentiation of baroreceptor reflex response through its expression in the nucleus tractus solitarii, the principal recipient of baroreceptor afferent fibers in the medulla oblongata. In fact, Hsp70 expression in the nucleus tractus solitarii after heat shock may alleviate severe hypotension and bradycardia observed during the onset of heatstroke by potentiating both the sensitivity and capacity of baroreceptor reflex response. ${ }^{45}$

Increased cellular levels of Hsp70 are also associated with the reduction of heat-induced permeability of an epithelial monolayer, ${ }^{46}$ thus probably representing an essential factor in preventing heat-associated endotoxin translocation across the gut. ${ }^{25}$ Similarly, the role of Hsp27 in protection of actin microfilament cytoskeleton under stress conditions may be important not only in individual cell tolerance to stress through cytoskeletal stabilization but may also be integral to the protection of the whole organism through the maintenance of endothelial and epithelial barrier integrity. ${ }^{25,47}$ In fact, systemic endotoxemia and elevations in circulating cytokines have been demonstrated to occur during heatstroke, ${ }^{48-50}$ and in this respect, reduction of gut flora by means of nonabsorbable antibiotics or administration of anti-endotoxin antibodies have been observed to allow animals to tolerate higher core temperatures. ${ }^{51,52} \mathrm{HSP}$-associated heat adaptation of the whole organism may also involve endotoxin tolerance, since cells and animals become endotoxin tolerant after Hsp70 accumulation. ${ }^{53-55}$ This endotoxin tolerance may be related to resistance to the direct effects of endotoxin or to cytokine exposure, or inhibition of cytokine production by inflammatory cells. ${ }^{25}$ In fact, macrophages stimulated to accumulate HSPs show both transcriptional inhibition and decreased secretion of TNF- $\alpha$ and IL-1. ${ }^{56,57}$ Likewise, a conditioning heat stress sufficient to cause Hsp70 accumulation is associated with a decrease in circulating TNF- $\alpha$ after endotoxin exposure. ${ }^{58}$ As well, cellular accumulation of HSPs has been demonstrated to confer resistance to the cytotoxic effects of inflammatory cytokines. ${ }^{32,59}$

Host conditions, such as aging, existing illness, dehydration, lack of acclimatization to heat, and certain genetic polymorphisms may be associated with a low level of HSP expression and might favor the progression from heat stress to heatstroke. ${ }^{18,60}$

\section{Pathophysiology of heatstroke}

Heatstroke is usually diagnosed when an acute onset of systemic clinical signs occurs in a previously healthy animal that presents with a core body temperature $>41^{\circ} \mathrm{C}\left(105.8^{\circ} \mathrm{F}\right)$, although it is important to underline that patients can also be normo- or even hypothermic on presentation, particularly if cooling measures are initiated by the owners or if they are in an advanced stage of shock. ${ }^{1-3,5}$ Heatstroke can be classified as either classic (nonexertional) or exertional. Classic heatstroke results from the exposure to high environmental temperatures, typically occurring in summer, and is seen in dogs that are confined in an overheated enclosure (eg, an unventilated automobile) or chained outdoors and deprived of water and shade. Exertional heatstroke may develop during strenuous physical exercise carried out in hot and humid environmental conditions, and it is usually seen in late spring or early summer before acclimatization occurs. ${ }^{4,6,8}$ On the other hand, it is uncommonly observed in well hydrated, acclimated, athletic, and working dogs despite activity in hot, humid environments. ${ }^{6}$

Several factors may also predispose dogs to the development of heatstroke: they can be divided into exogenous and endogenous conditions, which can either decrease the ability to dissipate heat or increase heat production. Predisposing factors include obesity, thick haircoat, geriatric age, brachycephalic anatomy, and upper airways, cardiovascular or neurologic diseases impairing physiologic cooling mechanisms. ${ }^{3-6,8,61-63}$ Use of certain drugs, such as phenotiazines, diuretics (eg, furosemide), or negative inotropic drugs, may also affect heat dissipation., ${ }^{4,6}$ In addition, metaldehyde, amphetamine, and macadamia nut intoxication may induce hyperthermia in dogs. ${ }^{4,64,65}$

Genetic polymorphisms could also determine susceptibility to heatstroke, and the likely candidate genes involved include those encoding cytokines, coagulation proteins, and HSPs. In this respect, the progression from heat stress to heatstroke is thought to be due to a combination of thermoregulatory 
failure, exaggeration of the acute-phase response to heat, and alteration in the expression of HSPs. ${ }^{7,18}$

On the basis of understanding of its pathophysiological mechanisms, heatstroke has been defined as a form of hyperthermia associated with hyperthermia-induced cytotoxicity, acute physiological alterations, systemic inflammatory response, oxidative damage, and attenuated heat shock response, leading to a syndrome of multiorgan dysfunction in which encephalopathy predominates. ${ }^{18,60}$ Harmful effects of hyperthermia are related to direct thermal injury and increased cellular metabolic demand and oxygen consumption: ${ }^{8}$ in particular, thermal injury causes widespread cellular necrosis through protein denaturation, inactivation of enzyme systems, destruction of cell-membrane lipids, and alteration of mitochondrial function. ${ }^{6}$

Even though the pathophysiological sequence of events occurring in canine heatstroke has not been completely investigated, it shares many similarities to that observable in sepsis. ${ }^{66}$ In the initial stages of heat stress, increased cardiac output and decreased systemic vascular resistance due to peripheral vasodilation occur, in order to shift circulation from the body core to the periphery. However, as hyperthermia progresses, splanchnic vasculature also dilates leading to venous pooling and a decrease in circulating plasma volume, which results in hypotension, decrease in cardiac output, and circulatory shock. With a decrease in circulating blood volume, heat dissipation mechanisms also fail, causing a further rise in body temperature and, thus, a progression of the cellular events underlying heatstroke. ${ }^{4,6}$ Global hypoperfusion and thermal-induced massive cellular destruction predispose to multiorgan dysfunction syndrome, the most serious complication of heatstroke, which may involve all body systems, although the most commonly affected organs are represented by the brain, kidney, gastrointestinal tract, liver, heart, and skeletal muscle. ${ }^{6,66}$

Myocardial damage may be secondary to direct thermal injury, decreased perfusion, acidosis, and electrolyte imbalance and predisposes the heart to conduction defects and ventricular arrhythmias, ${ }^{6,66,67}$ which are commonly observed in canine heatstroke. . $^{3,5,68}$

High sensitivity to hyperthermia, ischemia, and hypoxia of canine gastrointestinal tract has also been observed, ${ }^{66}$ and inflammatory cytokines and reactive oxygen and nitrogen species generated by the intestinal injured tissue may exacerbate mucosal damage, resulting in necrosis and hyperpermeability with subsequent potential for bacterial translocation and leakage of endotoxins into the bloodstream. ${ }^{1,3,18,69,70}$
The capillary and venous endothelia are also very susceptible to direct thermal injury, which in association with endotoxemia and cytokine production, may lead to increased vascular permeability and consequently to edema. Widespread endothelial damage may also result in tissue thromboplastin and factor XII release, with consequent activation of the coagulation and complement cascades, which may culminate in systemic inflammatory response syndrome (SIRS) and widespread microthrombosis and hemorrhagic diathesis as a result of disseminated intravascular coagulation (DIC). ${ }^{1,6,50,66,71}$ Thrombocytopenia, which is a common finding in canine heatstroke, may be due to direct heat damage to megakaryocytes or platelets, or may be associated with DIC. Hepatic damage due to thermal injury and prolonged splanchnic hypoperfusion may also further exacerbate hemostatic abnormalities. ${ }^{6}$

Acute renal failure associated with tubular degeneration and necrosis is another common sequel of heatstroke and occurs as a result of direct thermal injury, hypoperfusion, hypoxia, rhabdomyolysis causing myoglobinuria, endotoxemia, release of cytokines and vasoactive mediators, and microthrombosis secondary to DIC. ${ }^{1,3,6,66}$ DIC and acute renal failure have been found to be significant risk factors for death in canine heatstroke, and since DIC may appear hours to days after the initial heat insult, coagulation parameters and clinical signs of DIC should be monitored at least during the first 48 hours after insult. ${ }^{3,21}$ As well, clinical and laboratory features of acute primary renal failure may develop several days after the hyperthermic event, and although early and aggressive supportive therapy may allow dogs to regain a sufficient degree of renal function to cause remission of signs, ${ }^{72}$ permanent renal insufficiency or profound polyuria may also develop following recovery from heatstroke. ${ }^{6,16}$

Severe hyperthermia in dogs is also associated with cerebral hypoperfusion, direct vascular damage, cerebral and cerebellar edema, neuronal necrosis, hemorrhage and multifocal vascular thrombosis with tissue infarction that may lead to central nervous system dysfunction, which is a typical feature of heatstroke. Permanent brain damage may be caused by temperatures as low as $41^{\circ} \mathrm{C}\left(105.8^{\circ} \mathrm{F}\right),{ }^{17}$ and if involving the thermoregulatory center, it may predispose animals to subsequent hyperthermic episodes. ${ }^{6}$ Central nervous system signs in dogs range from transient fainting, disorientation/stupor, to cortical blindness, ataxia, seizures, or even semicoma/coma. However, given the intrinsic thermal resistance of the canine brain, other physiological derangements rather than the direct thermal insult, such as respiratory alkalosis, shock and hypoglycemia, have been 
suggested to play a major role in heatstroke-induced neurological dysfunctions. ${ }^{1-3,5,10}$ In particular, hypoglycemia can be a consequence of increased utilization or decreased production of glucose as a result of a generalized increased demand for ATP due to the elevated body temperature, hepatic failure, or sepsis that can develop because of intestinal mucosal damage and reduced host defenses. ${ }^{3,5}$

Other recorded complications of canine heatstroke include acute respiratory distress syndrome due to thermal and biochemical injury to pulmonary endothelium causing non-cardiogenic pulmonary edema, as well as pneumonia and pancreatitis. ${ }^{1,3}$

\section{Gross pathological findings in canine heatstroke}

On the basis of several reports describing the post-mortem changes in natural cases of canine heatstroke, the main, usually observable gross findings include generalized tissue congestion, edema, and hemorrhagic diathesis. 3,5,66,73

Examination of skin and mucous membranes may reveal multifocal petechiae and ecchymoses, as well as moderate to severe dermal hyperemia and edema. ${ }^{66,73}$ Severe, diffuse hyperemia and hemorrhages may also be observed in skeletal muscles, as well as on the visceral and parietal peritoneum, particularly the mesentery, in association with a serosanguineous intraperitoneal effusion, and in such cases the gastrointestinal tract usually demonstrates widespread hemorrhages in all layers, and blood-tinged fluid or even free blood may be present in the small intestinal lumen (Figure 1)..$^{3,66,73}$ These gastrointestinal lesions likely result in the clinically observable hematemesis, melena, or the gelatinous and bloody diarrhea frequently detected in canine heatstroke patients. . $^{1,3,5,66}$

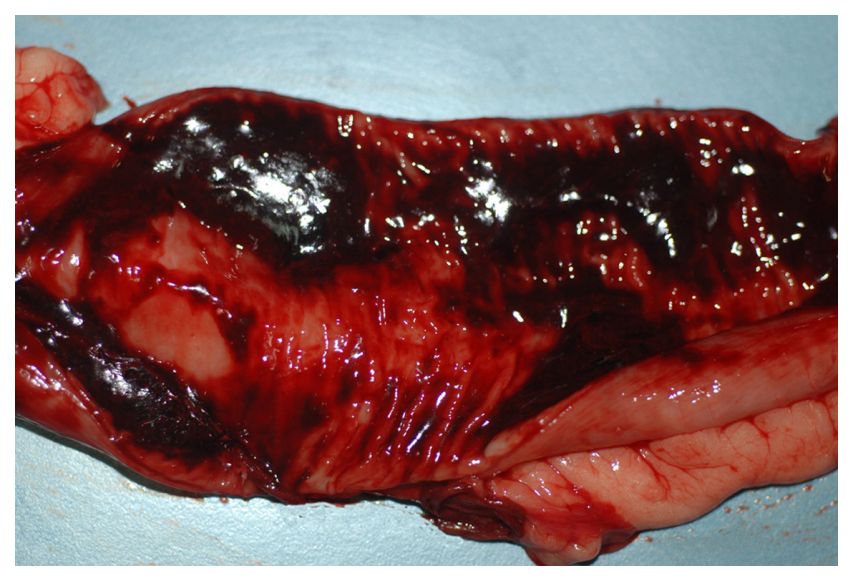

Figure I Dog, small intestine: severe, diffuse mucosal hyperemia, with abundant bloody fluid into the lumen.
Liver and spleen may show a moderately increased volume due to congestion, whereas kidneys may be variably swollen and commonly exhibit hemorrhages, which can be also found in urinary bladder mucosa. ${ }^{66}$ Pleural bloodtinged effusion may be occasionally detected, whereas the lungs frequently appear to be heavy, due to hyperemia and edema, with large volumes of frothy hemorrhagic fluid in the trachea and bronchial tree. ${ }^{12,66}$ Pulmonary infarction has been rarely recorded. ${ }^{5}$

Heart examination typically reveals mild to severe endocardial, myocardial, and epicardial hemorrhages (Figure 2), which can be associated with hemopericard. ${ }^{66}$ Meningeal and brain parenchymal hyperemia and edema, with focal cerebral hemorrhages, are also usually detectable (Figure 3). ${ }^{3,66}$ On the other hand, moderate bone marrow hyperemia, edema and hemorrhages may be rarely found. ${ }^{66}$

\section{Histopathological findings in canine heatstroke}

Microscopical lesions characterizing canine heatstroke generally reflect the gross pathological findings (ie, hyperemia, edema, hemorrhages, and necrosis), even though they can also be found in tissues and organs appearing grossly normal. In addition, it is important to remember that hemorrhagic lesions evidenced at histological examination have been reported to be associated with thrombosis of the adjacent microvasculature. ${ }^{66}$ In order of decreasing severity, cerebellum, cerebral cortex, heart, kidney and lung usually show histopathological changes. ${ }^{16}$

The Purkinje cells in the cerebellum are considered to be very susceptible to hyperthermia, ${ }^{6}$ and they frequently appear to be markedly degenerated, exhibiting hyperchromatic cytoplasm, loss of nuclear definition, and cytolysis.

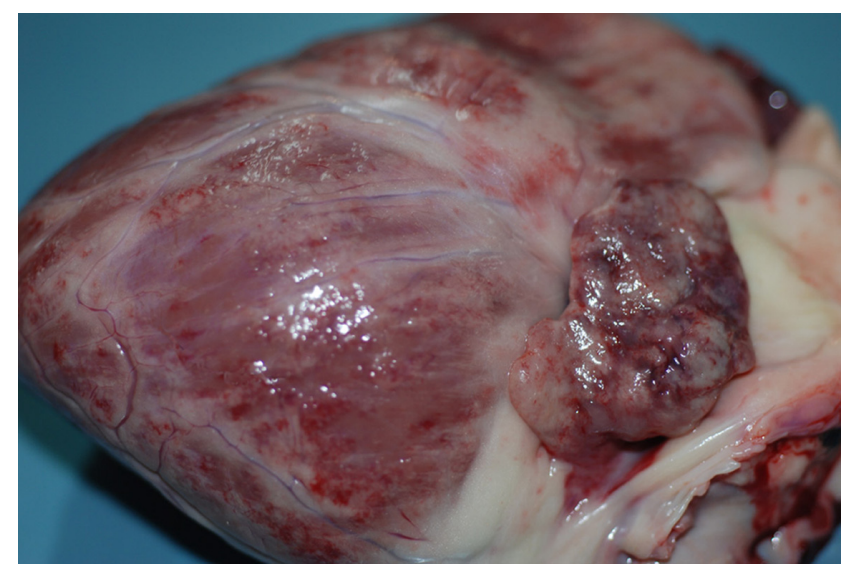

Figure 2 Dog, heart: moderate, multifocal epicardial hemorrhages. 


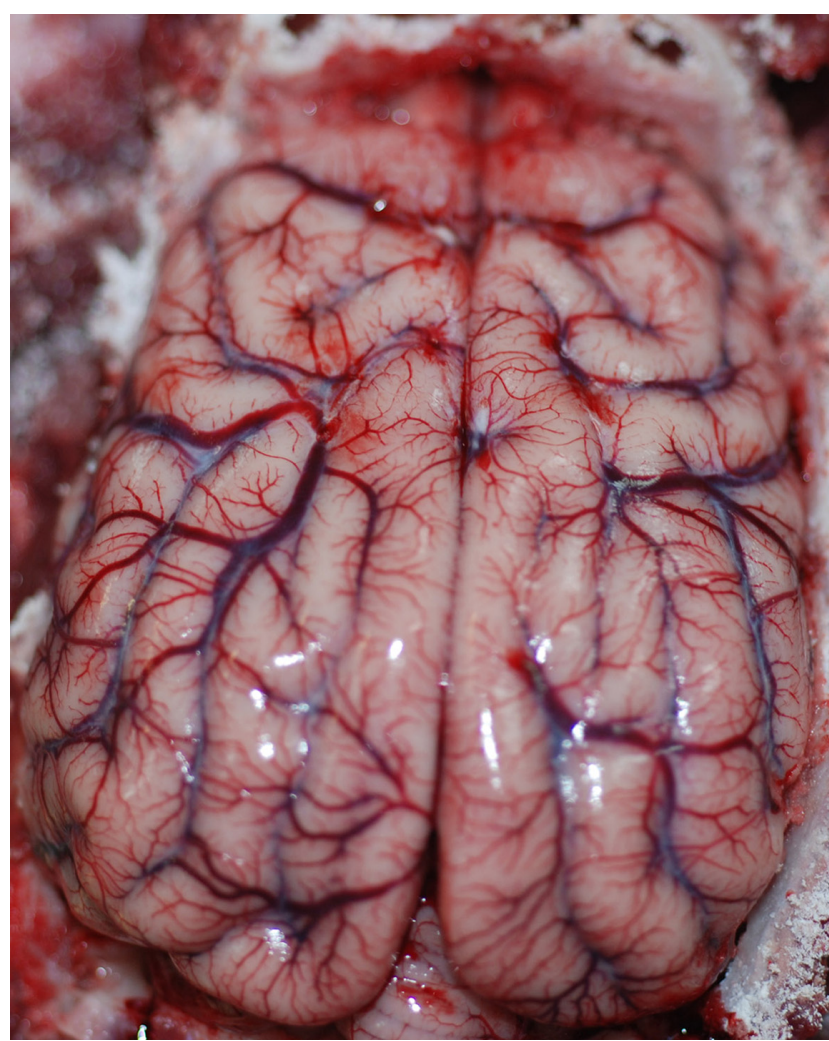

Figure 3 Dog, brain: intense and diffuse hyperemia.

Neuronal necrosis is also commonly seen in the cerebral cortex and to a lesser extent in the hippocampus. ${ }^{16,66}$

Heat-induced severe fragmentation of myocardial fibers and loss of myofibrillar striations may be observed in the canine heart; ${ }^{6,16}$ detection of swollen myofibers with hypereosinophilic sarcoplasm in skeletal muscle is also consistent with a diagnosis of hyperthermia. ${ }^{73}$

Renal lesions are common findings in canine heatstroke, even in absence of gross changes, and include interstitial and glomerular congestion, interstitial hemorrhages, tubular degeneration and necrosis of various degree, as well as renal infarcts. ${ }^{3,66}$

Microscopical pulmonary alterations usually consist of hyperemia, edema, multiple hemorrhages into interstitial tissue and alveoli, and occasional infarcts. . $^{1,5,16,66}$

Both the small and large intestine frequently show severe transmural congestion and hemorrhages, in association with various degree of necrosis of the mucosal epithelium. ${ }^{66,73}$ In the liver, sinusoid dilation causing compression of the adjacent hepatocytes and hypoxia may result in parenchymal necrosis, particularly in the centrolobular area. ${ }^{5,66}$

Another microscopical finding frequently reported in canine heatstroke patients is the detection of high numbers of nucleated red blood cells (nRBCs) at blood smear evaluation, which is considered a highly significant risk factor for death. ${ }^{74}$ This occurrence has been attributed to direct thermal bone marrow injury, as well as to endothelial damage and microvascular thrombosis associated with DIC, leading to lesions of blood-bone marrow barrier and subsequent premature release of nRBCs into the bloodstream. ${ }^{1,3,5}$ However, since a recent study failed to reveal microscopic disruption of bloodbone marrow barrier architecture, it has been alternatively hypothesized that the bone marrow $\mathrm{nRBC}$ release is mediated by cytokines produced during SIRS. ${ }^{66}$

\section{Conclusion}

Heatstroke is a life-threatening condition in which tissue and organ lesions depend on the primary thermal insult and the secondary hemodynamic deterioration, leading to serious complications, such as DIC, SIRS, and multiple organ dysfunction. Clinicopathological signs and prognosis of canine heatstroke depend on the duration and severity of hyperthermia. Early diagnosis and rapid initiation of cooling measures, as well as intensive and prolonged treatment and monitoring, may offer the best chance for survival. Heatstroke can be prevented by allowing for proper acclimatization, not forcing dogs to exercise in hot environments, and providing adequate access to water, shade, and ventilation.

\section{Disclosure}

The authors report no conflicts of interest in this work.

\section{References}

1. Bruchim Y. Canine heatstroke. Isr J Vet Med. 2012;67(2):92-95.

2. Flournoy WS, Macintire DK, Wohl JS. Heatstroke in dogs: clinical signs, treatment, prognosis, and prevention. Comp Cont Edu Pract Vet. 2003;25(6):422-431.

3. Bruchim Y, Klement E, Saragusty J, Finkeilstein E, Kass P, Aroch I. Heat stroke in dogs: a retrospective study of 54 cases (1999-2004) and analysis of risk factors for death. J Vet Intern Med. 2006;20:38-46.

4. Johnson SI, McMichael M, White G. Heatstroke in small animal medicine: a clinical practice review. JVet Emerg Crit Care. 2006;16(2): $112-119$.

5. Drobatz KJ, Macintire DK. Heat-induced illness in dogs: 42 cases (1976-1993). J Am Vet Med Assoc. 1996;209:1894-1899.

6. Flournoy WS, Wohl JS, Macintire DK. Heatstroke in dogs: pathophysiology and predisposing factors. Comp Cont Edu Pract Vet. 2003;25(6):410-418.

7. Yeo TP. Heat stroke: a comprehensive review. AACN Clin Issues. 2004;15(2):280-293.

8. Kelmer E, Kerl ME. Heat prostration. In: Morgan RV, editor. Handbook of Small Animal Practice, 5th ed. St Louis, MO: Saunders Elsevier; 2007:1257-1260.

9. Damanhouri ZA, Tayeb OS. Animal models for heat stroke studies. J Pharmacol Toxicol Methods. 1992;28(3):119-127.

10. Oglesbee MJ, Alldinger S, Vasconcelos D, et al. Intrinsic thermal resistance of the canine brain. Neuroscience. 2002;113(1):55-64.

11. Cheville NF. Introduction to Veterinary Pathology, 2nd ed. Ames, IA: Iowa State University Press; 1999. 
12. Daniel PM, Dawes JDK, Prichard MML. Studies of the carotid rete and its associated arteries. Phil Trans R Soc Lond B. 1953;237(645): 173-208.

13. Gillan LA. Blood supply to brains of ungulates with and without a rete mirabile caroticum. J Comp Neurol. 1974;153(3):275-290.

14. Frackowiak H, Godynicki S. Brain basal arteries in various species of Felidae. Pol J Vet Sci. 2003;6(3):195-200.

15. Fukuta K, Kudo H, Sasaki M, Kimura J, Ismail DB, Endo H. Absence of carotid rete mirabile in small tropical ruminants: implications for the evolution of the arterial system in artiodactyls. J Anat. 2007;210: 112-116.

16. Larson RL, Carithers BS, Carithers RW. A review of heat stroke and its complications in the canine. N Z Vet J. 1985;33:202-206.

17. Lewis S. Effect of heat on canine and feline. ISU Vet. 1976;38(3): 117-121.

18. Bouchama A, Knochel JP. Heat stroke. New Engl J Med. 2002;346(25): 1978-1988.

19. Horowitz M. From molecular and cellular to integrative heat defense during exposure to chronic heat. Comp Biochem Physiol A Mol Integr Physiol. 2002;131(3):475-483.

20. Horowitz M. Do cellular heat acclimation responses modulate central thermoregulatory activity? Physiology. 1998;13:218-225.

21. Johnson K. Pathophysiology of heatstroke. Comp Cont Edu Pract Vet. 1982;4(2):141-145.

22. Gabay C, Kushner I. Acute-phase proteins and other systemic responses to inflammation. $N$ Engl J Med. 1999;340(6):448-454. [Erratum in: N Engl J Med. 1999;340(17):1376].

23. Cray C, Zaias J, Altman NH. Acute phase response in animals: a review. Comp Med. 2009;59(6):517-526.

24. Xing Z, Gauldie J, Cox G, et al. IL-6 is an anti-inflammatory cytokine required for controlling local or systemic acute inflammatory responses. J Clin Invest. 1998;101(2):311-320.

25. Moseley PL. Heat shock proteins and heat adaptation of the whole organism. J Appl Physiol. 1997;83(5):1413-1417.

26. Mathew A, Morimoto RI. Role of the heat-shock response in the life and death of proteins. Ann N Y Acad Sci. 1998;851:99-111.

27. Whitley D, Goldberg SP, Jordan WD. Heat shock proteins: a review of the molecular chaperones. J Vasc Surg. 1999;29:748-751.

28. Nollen EAA, Morimoto RI. Chaperoning signaling pathways: molecular chaperones as stress-sensing 'heat shock' proteins. J Cell Sci. 2002;115: 2809-2816.

29. Ritossa F. A new puffing pattern induced by temperature shock and DNP in Drosophila. Experientia. 1962;18:571-573.

30. Tissieres A, Mitchell HK, Tracy UM. Protein synthesis in salivary glands of Drosophila melanogaster. Relation to chromosome puffs. J Mol Biol. 1974;84:389-398.

31. Morimoto RI. Regulation of the heat shock transcriptional response: cross talk between a family of heat shock factors, molecular chaperones, and negative regulators. Genes Dev. 1998;12:3788-3796.

32. Kregel KG. Heat shock proteins: modifying factors in physiological stress responses and acquired thermotolerance. J Appl Physiol. 2002; 92:2177-2186.

33. Didelot C, Schmitt E, Brunet M, Maingret L, Parcellier A, Garrido C. Heat shock proteins: endogenous modulators of apoptotic cell death. Handb Exp Pharmacol. 2006;172:171-198.

34. Kourtis N, Nikoletopoulou V, Tavernarakis N. Small heat-shock proteins protect from heat-stroke-associated neurodegeneration. Nature. 2012;490(7419):213-218.

35. Chang CK, Chang CP, Liu SY, Lin MT. Oxidative stress and ischemic injuries in heat stroke. Prog Brain Res. 2007;162:525-546.

36. Wang JL, Ke DS, Lin MT. Heat shock pretreatment may protect against heatstroke-induced circulatory shock and cerebral ischemia by reducing oxidative stress and energy depletion. Shock. 2005;23(2): $161-167$.

37. Horowitz M, Maloyan A, Shlaier J. HSP $70 \mathrm{kDa}$ dynamics in animals undergoing heat stress superimposed on heat acclimation. Ann NY Acad Sci. 1997;813:617-619.
38. Maloyan A, Palmon A, Horowitz M. Heat acclimation increases the basal HSP72 level and alters its production dynamics during heat stress. Am J Physiol Regul Integr Comp Physiol. 1999;276:R1506-R1515.

39. Yamada PM, Amorim FT, Moseley P, Robergs R, Schneider SM. Effect of heat acclimation on heat shock protein 72 and inteleukin-10 in humans. J Appl Physiol. 2007;103:1196-1204.

40. Yang YL, Lu KT, Tsay HJ, Lin CH, Lin MT. Heat shock protein expression protects against death following exposure to heatstroke in rats. Neurosci Lett. 1998;252(1):9-12.

41. Yang YL, Lin MT. Heat shock protein expression protects against cerebral ischemia and monoamine overload in rat heatstroke. Am J Physiol. 1999;276:H1961-H1967.

42. Lee WC, Wen HC, Chang CP, Chen MY, Lin MT. Heat shock protein 72 overexpression protects against hyperthermia, circulatory shock, and cerebral ischemia during heatstroke. J Appl Physiol. 2006;100:2073-2082.

43. Ahmed RG. Heat stress induced histopathology and pathophysiology of the central nervous system. Int J Dev Neurosci. 2005;23:549-557.

44. Dehbi M, Baturcam E, Eldali A, et al. Hsp-72, a candidate prognostic indicator of heatstroke. Cell Stress Chaperone. 2010;15(5):593-603.

45. Li PL, Chao YM, Chan SHH, Chan JYH. Potentiation of baroreceptor reflex response by heat shock protein 70 in nucleus tractus solitarii confers cardiovascular protection during heatstroke. Circulation. 2001;103:2114-2119.

46. Moseley PL, Gapen C, Wallen ES, Walter ME, Peterson MW. Thermal stress induces epithelial permeability. Am J Physiol. 1994;267(2 Pt 1): C425-C434.

47. Lavoie JN, Gingras-Bretan G, Tanguay RM, Landry J. Induction of Chinese hamster HSP27 gene expression in mouse cells confers tolerance to heat shock. HSP27 stabilization of the microfilament organization. J Biol Chem. 1993;268(5):3420-3429.

48. Bouchama A, Parhar RS, El-Yazigi A, Sheth K, Al-Sedairy S. Endotoxemia and release of tumor necrosis factor and interleukin-1 alpha in acute heatstroke. J Appl Physiol. 1991;70:2640-2644.

49. Leon LR. Heat stroke and cytokines. Prog Brain Res. 2007;162: 481-524.

50. Leon LR, Helwig BG. Role of endotoxin and cytokines in the systemic inflammatory response to heat injury. Front Biosci (Schol Ed). 2010;2: 916-938.

51. Gathiram P, Wells MT, Brock-Utne JG, Gaffin SL. Antilipopolysaccharide improves survival in primates subjected to heat stroke. Circ Shock. 1987; 23(3):157-164.

52. Gathiram P, Wells MT, Brock-Utne JG, Wessels BC, Gaffin SL. Prevention of endotoxaemia by non-absorbable antibiotics in heat stress. J Clin Pathol. 1987;40:1364-1368.

53. Chi S, Mestril R. Stable expression of a human HSP70 gene in a rat myogenic cell line confers protection against endotoxin. Am J Physiol. 1996;270(4 Pt 1):C1017-C1021.

54. Hotchkiss R, Nunnally I, Lindquist S, Taulien J, Perdrizet G, Karl I. Hyperthermia protects mice against the lethal effects of endotoxin. Am J Physiol. 1993;265(6 Pt 2):R1447-R1457.

55. Ryan AJ, Flanagan SW, Moseley PL, Gisolfi CV. Acute heat stress protects rats against endotoxin shock. J Appl Physiol. 1992;73: 1517-1522.

56. Snyder YM, Guthrie L, Evans GF, Zuckerman SH. Transcriptional inhibition of endotoxin-induced monokine synthesis following heat shock in murine peritoneal macrophages. J Leukoc Biol. 1992;51:181-187.

57. Ensor JE, Wiener SM, McCrea KA, Viscardi RM, CrawfordEK, Hasday JD. Differential effects of hyperthermia on macrophage interleukin-6 and tumor necrosis factor-a expression. Am J Physiol. 1994;266(4 Pt 1): C967-C974.

58. Kluger MJ, Rudolph K, Soszynski D, et al. Effect of heat stress on LPS-induced feverand tumornecrosis factor. AmJPhysiol. 1997;273(3 Pt2): R858-R863.

59. Hung CH, Chang NC, Cheng BC, Lin MT. Progressive exercise preconditioning protects against circulatory shock during experimental heatstroke. Shock. 2005;23(5):426-433. 
60. Yan YE, Zhao YQ, Wang H, Fan M. Pathophysiological factors underlying heatstroke. Med Hypotheses. 2006;67(3):609-617.

61. Durkot MJ, Francesconi RP, Hubbard RW. Effect of age, weight, and metabolic rate on endurance, hyperthermia, and heatstroke mortality in a small animal model. Aviat Space Environ Med. 1986;57(10 Pt 1):974-979.

62. German AJ. The growing problem of obesity in dogs and cats. J Nutr. 2006;136:1940S-1946S.

63. Blackmore JA, Schaer M. Idiopathic polyradicoloneuritis and impaired ventilation in a dog. A case report. J Am Anim Hosp Assoc. 1984;20(3):487-490.

64. Stowe CM, Werdin RE, Barnes DM, et al. Amphetamine poisoning in dogs. J Am Vet Med Assoc. 1976;168(6):504-506.

65. Hansen SR, Buck WB, Meerdink G, Khan SA. Weakness, tremors, and depression associated with macadamia nuts in dogs. Vet Hum Toxicol. 2000;42(1):18-21.

66. Bruchim Y, Loeb E, Saragusty J, Aroch I. Pathological findings in dogs with fatal heatstroke. J Comp Path. 2009;140:97-104.

67. Ferrier GR, Moffat MP, Lukas A. Possible mechanisms of ventricular arrhythmias elicited by ischemia followed by reperfusion. Studies on isolated canine ventricular tissues. Circ Res. 1985;56(2):184-194.
68. Mellor PJ, Mellanby RJ, Baines EA, Villiers EJ, Archer J, Heritage ME. High serum troponin I concentration as a marker of severe myocardial damage in a case of suspected exertional heatstroke in a dog. $J$ Vet Cardiol. 2006;8(1):55-62.

69. Hall DM, Baumgardner KR, Oberley TD, Gisolfi CV. Splanchnic tissues undergo hypoxic stress during whole body hyperthermia. Am J Physiol. 1999;276:G1195-G1203.

70. Hall DM, Buettner GR, Oberley LW, Xu L, Matthes RD, Gisolfi CV. Mechanisms of circulatory and intestinal barrier dysfunction during whole body hyperthermia. Am J Physiol Heart Circ Physiol. 2001;280:H509-H521.

71. Leon LR, Helwig BR. Heat stroke: The role of systemic inflammatory response. J App Physiol. 2010;109:1980-1988.

72. Krum SH, Osborne CA. Heatstroke in the dog: a polysystemic disorder. J Am Vet Med Assoc. 1977;170(5):531-535.

73. Bosak JK. Heat stroke in a Great Pyrenees dog. Can Vet J. 2004;45: 513-515.

74. Aroch I, Segev G, Loeb E, Bruchim Y. Peripheral nucleated red blood cells as a prognostic indicator in heatstroke in dogs. Vet Intern Med. 2009;23(3):544-551.

\section{Publish your work in this journal}

Veterinary Medicine: Research and Reports is an international, peer-reviewed, open access journal publishing original research, case reports, editorials, reviews and commentaries on all areas of veterinary medicine. The manuscript management system is completely online and includes a very quick and fair peer-review system.

\section{Dovepress}

Visit http://www.dovepress.com/testimonials.php to read real quotes from published authors. 